\title{
Collaboration between applied and computer optics department of ITMO University with industry's leading manufacturers
}

\section{Alexey Bakholdin, Kseniia Ezhova, Anna Voznesenskaya, Tatiana Ivanova, Galina Romanova, et al.}

Alexey Bakholdin, Kseniia Ezhova, Anna Voznesenskaya, Tatiana Ivanova, Galina Romanova, Nadezhda Tolstoba, "Collaboration between applied and computer optics department of ITMO University with industry's leading manufacturers," Proc. SPIE 9793, Education and Training in Optics and Photonics: ETOP 2015, 97932F (8 October 2015); doi: 10.1117/12.2223214

SPIE Event: Education and Training in Optics and Photonics: ETOP 2015, 2015, Bordeaux, France 


\title{
Collaboration between Applied and computer optics department of ITMO University with industry's leading manufacturers
}

\author{
Alexey Bakholdin, Kseniia Ezhova*, Anna Voznesenskaya, Tatiana Ivanova, Galina Romanova, \\ Nadezhda Tolstoba \\ ITMO University (Russian Federation)
}

\begin{abstract}
Modern higher education could not function without a close connection of universities and industry's leading manufacturers. The article discusses collaboration between Applied and computer optics department of ITMO University with industry leaders. Features collaboration, problems and results of its implementation are presented in the article
\end{abstract}

Keywords: graduation practical training, collaboration, education in optics

\section{INTRODUCTION}

Preparation of specialists in higher education directed to getting by students not only theoretical knowledge but also practical experience and skills necessary for further successful work in the chosen direction.

To a large extent, the possible forms of collaboration with leading industry organizations are determined research areas, developing in the department, and in particular the university as a whole.

ITMO University is one Russia's leading higher education and research institutions, specializing in Information Technology, Optical Design and Engineering. Founded in 1900, today it is home to over 13,000 students and has earned its name "National Research University," blending the culture of innovation and discovery with world-class education. Departments offer an extensive curriculum in fundamental and applied disciplines, with an emphasis on graduate education and multidisciplinary approach. Focus is on preparing elite scientists, engineers and programmers, notably in the areas of Photonics and Optics, Intelligent Technology and Robotics, Computer Science and Information Technology, Life Sciences, Natural sciences, Smart- and Nano- materials and Technology [1].

\section{MAIN RESEARCH AREAS OF APPLIED AND COMPUTER OPTICS DEPARTMENT}

Department of Applied and computer optics is the successor of the oldest Russian optical departments - the Department of the theory of optical devices, of physiological optics, of optical devices, of laboratory, and then opto-mechanical devices. Briefly basic scientific directions of Applied and computer optics department and tasks that are solved in accordance with the direction possible to determine as follows [2]:

1. Design and modeling of optical systems:

- Design of high-quality optical systems for different purposes (micro optics, astronomical optics, etc.);

- Design of illumination optical system with different light sources, including LED;

- Modeling of optical and optoelectronic systems using optical design software;

- Lightening modeling and visualization.

2. Hologram optics and devices:

- Analysis of the features of imaging properties for discrete digital and computer generated holograms;

- Creation of methods for design and manufacturing physically recorded and computer generated hologramprojectors for using in photolithography process instead of projector lenses;

- Design and manufacturing of devices with diffraction type combiners, such as holographic weapon sights and devices closed to Google glasses.

*ezhovakv@aco.ifmo.ru; phone +7 812 595-4165; en.ifmo.ru

Education and Training in Optics and Photonics: ETOP 2015, edited by Eric Cormier, Laurent Sarger Proc. of SPIE Vol. 9793, 97932F · @ 2015 SPIE, IEEE, OSA, ICO · doi: 10.1117/12.2223214 


\section{Design of optical devices:}

- Design of optical units and optical instruments for different purposes (ophthalmology, microscopy, medicine, geodesy, metrology, space telescope, etc.);

- Development of lightweight large-size optical elements and astronomical mirrors.

4. Optical systems and elements testing:

- Computer-aided measurement processing;

- Telescope and large-size optical elements quality testing.

5. Automated engineering of optical instruments:

- Setting up the environment of CAD (AutoCAD, KOMPAS-3D, etc.) for the lifecycle management of the device within the company and automated documentation release;

- Software CADOptix is purposed for design and technical documentation release;

- Automated drawing of lenses and mirrors in KOMPAS-3D.

6. Computational optics:

- Ray tracing through optical elements;

- Automation of optical system design;

- Import / export optical design data (Zemax, OPAL, SARO);

- Macro programming for Zemax;

- Optimization of geometrical and optical parameters for special optical elements (GRIN lenses, conic lightguides, liquid lenses, etc.);

- Optical material database http://glassbank.ifmo.ru;

- Russian glasses catalog for Zemax.

7. Image processing and analysis:

- Software development for image processing and analysis;

- Using basic computer image processing algorithms and their application;

- Methods of image restoration and stabilization;

- Interpolation algorithms, which are used during registration by matrix sensor;

- Methods of 3D images generation.

\section{COLLABORATION FORMS ACO DEPARTMENT WITH INDUSTRY COMPANIES}

Historically Applied and computer optics department of ITMO University maintains contacts with leading optical and opto-mechanical manufacture of Russia.

The collaboration possibility of the Department with the leading companies of optoelectronic instrument engineering caused including those the fact that most of the scientific and production departments in the field of applied optics in Russia, as well as many in the United States, Israel and China, are led by graduates of our scientific school [2].

Collaboration is carried out on various directions:

- leading specialists of the industry companies participation in the work education plans discussions that allows to correct developed plans in accordance with the actual requirements of potential employers;

- leading specialists of the industry companies participation in the work programs assessment as experts in disciplines that allows to modify the content of the disciplines to maintain the prove relevant and compelling of students studying knowledge;

- leading specialists of the industry companies participation in teaching lectures on the modern trends of optical engineering, which allows students to get the most actual information about current problems and methods of their solutions in the field of optical engineering;

- leading specialists of the industry companies participation in the work of state examination commission on defence of thesis of final qualification work as members and chairman of the commission. It needs to provide an 
objective knowledge assessment of graduates, to get recommendations for further development of graduation qualification papers themes and trends and, of course, it helps to acquaint the graduates with potential employers;

- conclusion of contracts on execution of industrial and research practices based on manufacturing facilities that allows students from the department to actively participate in solving modern actual practical problems in the field of optical and opto-electronic instrument engineering and acquire practical skills using the accumulated theoretical knowledge;

- carrying out of joint scientific research aimed at solving contemporary optical engineering tasks with the faculty assistance, which allows professors of the department to use the practical tasks as an example in the disciplines contents;

- specialists of the industry companies participation in the international optical seminar, annually held at the Applied and computer optics department of ITMO University, which gives an opportunity to discuss urgent issues of industry, to take part in workshops devoted to modern software used in optoelectronic instrument that allows students and faculty of the department regularly improve their qualifications.

All of this allows students and faculty of the department to obtain the most topical information on current trends in the field of optical and optoelectronic instrumentation, organize educational process with examples of actual problems of optical engineering solutions, consider the requirements of potential employers to the scope and content of the curriculum.

\section{ORGANIZATION OF GRADUATION PRACTICAL TRAINING AT THE COMPANIES}

Special attention is given to graduation practice and writing final qualifying works both in a bachelor degree education, and a master's degree education.

Currently, more than $70 \%$ of the students and masters graduation works at the department is carried out in collaboration with companies in the sector.

In particular, students do their practical work, that provided by the department curriculum, on the basis of such large enterprises as:

- Federal State Unitary Enterprise Scientific and Industrial Corporation "Vavilov State Optical Institute",

- branch office of FSUE central research institute "Cometa" - "Research and design center for optoelectronic surveillance complexes",

- $\quad$ PLC "LOMO",

- $\quad$ "Schwabe-St.Petersburg" (branch office of Ural opto-mechanical manufactory).

During practical training, students get to know to the structure of the company, organization of the working process for finding a solution to get specific tasks connected with the current project, developed by the company.

Each student is assigned a practice leader at the company and the curator practice from the staff of the department.

At the end of practice the student must prepare a report and a presentation about the work done, which should include the following items: the tasks for a work, the main stages of the work, methods and ways of solving the problem, results of the work, the conclusions of the work done. The report should be submitted to the department.

Often, tasks which was solved during the period of practice, become the basis for further work and determine the direction and theme of final qualifying work. 


\section{COLLABORATION WITH THE COMPANY DURING THE PREPARATION OF FINAL QUALIFYING WORKS}

As already noted, often final qualifying work becomes an extension of problem solving, acquaintance with which was during the practical training at one of the industry company.

It should be noted quite a wide range of problems solved by students when writing final papers due to the specializations of the Bachelor and Masters programs at the department and with the directions of enterprise activity: development of algorithms and the creation of software systems designed to solve various problems of the optical orientation, development and modeling environments in automated design of optics optical systems for various applications, automation of designing optical elements and systems and etc.

Over the years these final qualifying work is deservedly are marked as one of the best when defence of thesis, thanks to the complex combination of theoretical and practical knowledge acquired by students in the learning process and practical training on the basis of leading companies

Commission for the defence of thesis, in accordance with state educational standards, is formed so that one of the leading experts of the industry in the composition of the commission is not less than $20 \%$. This allows more objectively evaluate the student's work done and its relevance, conformity with modern trends of development of optoelectronics.

Final qualifying work necessarily peer reviewed by leading experts optoelectronics companies of St. Petersburg, which are selected supervisors together with the head of the Department of Applied and computer optics depending on the focus theme of final qualifying work.

Thus, the preparing and the final defense of the final qualification works is also one of the most important forms of collaboration of the Department of Applied and computer optics with the leading companies of the industry.

\section{CONCLUSION}

Cooperation between the department and industry leaders can be carried in different ways, but it should be complex and include not only educational, but also organizational and scientific process.

Only in this case, the close connection between the educational institution and the company is formed, which allows the company to get oriented young professionals, and the university to adjust educational programs and content of courses in accordance with the current issues of the industry.

\section{REFERENCES}

[1] ITMO University. http://en.ifmo.ru/

[2] Applied and Computer Optics department. http://aco.ifmo.ru/about_eng.html 